\title{
DE TIENDE ZITTING VAN HET INSTITUT INTERNATIONAL DE STATISTIQUE.
}

Dreigden als gevolg van overlading van het werkprogramma de zittingen van het Institut International de Statistique te zullen gaan lijden aan hetzelfde euvel hetwelk groote congressen pleegt te kenmerken, t. w. onvoldoende voorbereiding en oppervlakkige behandeling der in discussie komende onderwerpen, met voldoening mag worden geconstateerd, dat de in opdracht der regeering door mij bijgewoonde tiende zitting van het Institut, van $31 \mathrm{Juli}-5$ Augustus 1905 te Londen gehouden, zich in dit opzicht gunstig van de beide laatstvoorafgaande zittingen onderscheidt. Ten einde an de van meerdere zijden kenbaar gemaakte wenschen te voldoen, was het programma der werkzaamheden door het Bureau ditmaal vergelijkenderwijze 7eer beperkt. Toch blijft er in dit opzicht nog veel te doen. Voor een vijftal dagen is een dagorde van 18 verschillende onderwerpen, waaronder verscheidene van welke vooraf vaststond dat zij tot uitvoerige discussiën zouden aanleiding geven ${ }^{1}$ ), beslist te uitgebreid. En zulks te meer omdat de onvermijdelijke formaliteiten ter gelegenheid van opening en sluiting, de verkiezingen en de huishoudelijke werkzaamheden, van den beperkten tijd steeds een te groot deel plegen in beslag te nemen.

Het werkplan behoort, naar mijne meening, zoo beknopt te wezen, dat eene splitsing der vergadering in secties omoodig is. Het Institut beperkt, zeer terecht, zijn ledental, met het gelukkig gevolg dat het schier uitsluitend bestaat uit beroepsstatistici, hetzij dan producenten of consumenten van statistiek. Bij de tegenwoordige neiging tot centralisatie op statistisch

1) En wederom enkele (zooals het pleidooi van Y. Guyot ten gunste van den vrijhandel, al was dit pleidooi ook in een statistisch gewaad gestoken) welke op deze vergadering misplaatst waren.

Econ. 1905. 
gebied ziju echter althans de producenten der statistiek geïnteresseerd bij de meest uiteenloopende onderdeelen van het statistisch waarnemingsveld. Doch de verdeeling van de vergadering in secties maakt het hun onmogelijk de beraadslagingen volledig te volgen. Wel komt de vrucht van het in de secties behandelde later, in den vorm van conclusies, nog eens in de algemeene vergadering ter sprake; doch dan pleegt daarover, althans in den regel, begrijpelijkerwijze geeu beraadslaging meer gevoerd te worden. Ook ditmaal echter werd de vergadering weder in drie secties verdeeld die vergaderden onder voorzitterschap der heeren von Mayr, Yves Guyot en Delatour. Nu intusschen de wensch van hen, die een klein werkprogramma verlangen, bij het Bureau weerklank blijkt te vinden, mag meu hopen, dat de eerstvolgende zitting van nog meerderen vooruitgang in deze richting zal blijk geven en de secties danr zullen verdwenen zijn.

Nog een ander punt verdient $\mathrm{m}$. i. ernstige overweging, n.l. verlenging van de intervallen der zittingen. Thans komt het Institut om de twee jaren bijeen. Deze termijn is naar het mij voorkomt te kort en zoude veilig verdubbeld kunnen worden. De daarmede gepaard gaande besparing van kosten zou de mogelijkheid openen, dat de door het Institut ter bestudeering van verschillende vragstukken benoemde commissies in den tijd tusschen twee zittingen van het Instituut mondeling overleg pleegden wanneer dit noodig bleek; en voorts, dat hare rapporten een behoorlijken tijd vóór de bijeenkomst van het Institut in welke zij moeten wordeu belandeld in handen kwamen der leden, die zich zoodoende, beter dan thans veelal mogelijk is, op de beraadslagingen zouden kunnen voorbereiden. Een en ander zou stellig aan het gehalte der zittingen ten goede komen.

Hoe dit zij, men is thans in het Institut, blijkens de beperking van het werkprogramma, op den goeden weg en het is daarom dubbei te betreuren, dat de zitting van Londen zoo slecht is bezocht geweest. Niet alleen hadden de Engelsche statistici (Booth, Eidgeworth, Giffen, Marshal) zich zeer teruggehouden, ook de opkomst der leden was ditmaal slecht. Van het Bureau ontbraken niet minder dan 3 van de 6 leden: Levasseur (wegens droevige familie-omstandigheden), Troïnitzky en Bodio. En onder de leden miste men o. m. noode: Bertillon, 
von Körösy, von Juraschek, Hirschberg, Mischler, Waxweiler, Foutaine, Moron, de Negri, Guillaume en anderen, welke tot de getrouwe deelnemers aan de zittingen van het Institut plegen te behooren. De beraadslagingen stonden dientengevolge niet steeds op het peil, dat zij bij meer bevredigende opkomst der leden zouden hebben bereikt.

Toch is de Londeusche zitting van het Institut in verschillend opzicht belangrijk geweest. Alvoreus van bet verhandelde in de secties (voorzoover deze door mij konden worden bijgewoond) en de op grond daarvan genomen besluiten verslag te doen, volgen hier enkele mededeelingen van algemeenen aard.

De zitting had het voorrecht door den Prins van Wales, die het eere-voorzitterschap bekleedde, te worden geopend. In welgekozen bewoordingen de ontwikkeling der statistiek herdenkend, sedert in 1860 onder voorzitterschap van zijn grootvader Prins Albert het statistisch congres te Louden bijeenkwam, wees Z. K. H. terecht op het groote gewicht eener betrouwbare statistiek als hulpbron voor de wetenschap en als gids voor de administratie. In the future, verklaarde hij met juistheid, all branches of social science must look for their advancement and increase of precision to the continually improving character of the raw material furnished them by statistics. Men mocht wenschen dit inzicht meer algemeen verbreid te zien.

De algemeene vergaderingen waren verder, behalve an de stemmingeu over de besluiten der secties en het aanhooren van enkele algemeene opmerkingeu van Prof. Mandello (Pressburg) over de toekomst der statistiek, gewijd aan huishoudelijke aangelegenheden. Eeu nieuw kiesreglement werd op voorstel van Nicolaï (Brussel) vastgesteld. In de bestaande vacaturen werden uit de voorgestelde candidaten 13 nieuwe leden van het Institut gekozen, waarvan 4 uit Duitschland, 3 uit Frankrijk, 2 uit Engeland en 1 resp. uit Oostenrijk, Zwitserland, Denemarken en Egypte. Het Burenu vau het Institut werd met eenstemmigheid herkozen, voor zooveel betreft deu Voorzitter (von Inama Sternegg, Weeuen), de Ondervoorzitters (Levasseur, Parijs, Lexis, Göttingen en Troïnitzky, Petersburg) en den Penniugmeester (Bateman, Londen). De algemeene secretaris, Bodio (Rome) had ontslag gevraagd, hetwelk hem werd verleend onder toekenning van den titel van eere-secretaris, als eene rechtmatige 
hulde voor zijne vele verdiensten jegens de strtistiek en het Institut, welks secretaris hij vanaf de oprichting was geweest. Aangezien ondergeteekende, aangezocht om als algemeen secretaris in het Bureau zitting te nemen, verzocht de benoeming tot de volgende zitting vau het Institut aan te houden, bleef het secretariaat voorloopig vacant en werd het comité van organisatie der Londensche zitting, met den heer Craigie aan het hoofd, uitgenoodigd zich met het opmaken van het verslag te willen belasten.

Thans overgaande tot het verhandelde in de secties en de door het Institut genomen besluiten, vinde in de eerste plaats vermelding de discussie over het door March (Parijs) uitgebracht rapport van het Comité voor de bedrijfstellingen en de werkloosheid-statistiek, aan welk rapport ook door mij, als lid van het comité, was medegewerkt. Terwijl met betrekking tot de kwestie der bedrijfstellingen vrij spoedig overeenstemming werd verkregen ten opzichte van de zich tot enkele hoofdpunten bepalende conclusien, ontspon zich eene uitvoerige en levendige gedachtenwisseling over de mogelijkheid om door middel van algemeene tellingen te geraken tot eene juiste kennis van den omvang der werkloosheid. Het waren de heer Llewellyu Smith en de ondergeteekende die deze mogelijkheid betwistten, waartegenover de rapporteurs, gesteund door de heeren Nicolaï (Brussel), Cheysson (Parijs), Mataja (Weenen) en Silbergleit (Maagdenburg) volhielden, dat de statistiek zich niet mocht onttrekken aan de taak, om dit zoozeer de publieke aandacht in beslag nemend ziekteverschijnsel in aard en omvang te doen kenneu. De gegrondheid der bezwaren tegen de betrouwbaarheid der tot dusver verschenen werkloosheid-statistieken aangevoerd, werd door hen niet betwist. Nochtans meenden zij, dat de statistische methode ook op dit gebied gaandeweg meer volkomen zoude worden en tot steeds beter resultaten leiden. De moeielijkheid zit echter niet zoozeer in de gebreken van het instrument der massale waarneming als zoodanig, doch in de onmogelijkheid om het begrip "werkloosheid" z6́ scherp te belijnen, dat het door allen tot wie de vraaglijst komt in gelijken zin wordt opgevat. En juist op dit punt zijn de tot dusver gehouden tellingen — van opzettelijke onjuistheden in de beantwoording 
nog afgezien - droevig te kort geschoten. De omvang der werkloosheid en de stand der arbeidsmarkt moeten daarom langs andereu weg (vakvereenigingen, arbeidsbeurzen) worden onderzocht, viet met het hier ondeugdelijk middel der algemeene telling.

De oppositie mocht echter niet baten. De conclusien van de rapporteurs werden door de sectie met groote meerderheid van stemmen aangenomen, en later door het plenum bekrachtigd. Zij luiden aldus:

Dans les pays où il est possible de procéder à des recensements industriels généraux, l'Institut International de Statistique recommande les dispositions suivantes, applicables au minimum des renseignements que doivent fournir ces recensements.

1. Comprendre dans la populatiou active les personnes occupées à un travail rémunéré, y compris les personues momentanément sans travail; ne pas y comprendre les membres de la famille exclusivement occupés aux travaux du ménage, ceux-ci étant comptés à part.

2. Lorsque, pour 'les exploitations fonctionnant au domicile du chef de l'exploitation, on compreud dans la population active les membres de la famille prenant une certaine part aux travaux de l'exploitation, avoir soin de former une catégorie spéciale de ces personnes.

Dans les comparaisous internationales, laisser en dehors des comparaisons les femmes, et les enfants de moins de 20 ans, des chefs de ces exploitations.

3. Un recensement général est nécessaire pour counaître toutes les personnes qui, ordinairement employées dans un établissement, se trouvent momentanément sans place, et pour classer ces personnes suivant l'etat civil (sexe, âge, etc.), la profession, la durée du chômage actuel.

Diviser la durée de manière à permettre de former les catégories suivantes:

1 semaine-2 semaines -3 à 4 semaines (1 mois)--5 à 13 semaines (l à 3 mois)-14 à 26 semaines ( 3 à 6 mois)27 à 51 semaines ( 6 mois à 1 an) -52 semaines et plus ( 1 an et plus).

Dans les comparaisous, ne pas comprendre les personnes sans emploi âgées de plus de 60 ans ou en chômage depuis un an et plus. 
4. Le recensement général ne permettant ordinairement pas de recueillir des renseignements assez fréquents, ou assez circonstanciés, sur l'importante question du chômage, compléter les données du recensement par des enquêtes partielles (associations professionnelles, chefs d'entreprises, institutions de placement ou de secours, etc.)

5. Pour grouper correctement les personnes actives par catégories professionnelles, les classer en premier lieu, d'après l'industrie collective exercée dans chaque établissement de la localité de recensement, où le travail en commun s'effectue sous la direction d'un ou de plusieurs représentants d'une même firme. Lorsque plusieurs industries connexes sont exercées dans un même établissement, on pourra n'avoir égard, dans ce premier classemeut, qu'à l'industrie principale, celle qui occupe le plus grand nombre de personnes.

6. Suivant la situation dans l'industrie ou la profession, distinguer en première ligue les quatre groups suivants:

(a) Chefs d'établissement.

(b) Employés et ouvriers des établissements.

(c) Employés et ouvriers sans emploi.

(d) Travailleurs isolés et personnes à emploi irrégulier dont les limites résultent de la définition de l'établissement.

7. Pour la population active totale, classée au moins suivant le sexe et suivant la position, former autant de catégories industrielles qu'il y a dans le pays d'industries exercés par des établissements différents.

8. Pour le classement des établissements suivant l'importance faire en sorte que l'on puisse former les catégories suivantes: 0 employé.

1 -5 employés ou ouvriers 501 " 2000 " " $6-20$ " " " plus de 2000 " " $21-100 "$ " "

(détailler les établissements de plus de 2000 ouvriers).

9. En ce qui concerne les classements suivaut les conditions d'état civil, se reporter aux résolutions antérieures de l'Institut International de Statistique.

Ter zitting van Budapest was, naar aauleiding mijner mededeeling over de uitkomsten van het destijds hier te lande ingesteld 
onderzoek naar het verband tusschen welstand, nataliteit en kindersterfte, het vroeger te Bern benoemde comité ter bestudeering van het vragstuk der bevolkingsregisters opnieuw geconstitueerd met aanwijzing van den heer Nicolaï (Brussel) als rapporteur. Deze had de behandeling van het onderwerp voor de Londensche zitting voorbereid in een uitnemend rapport, waarvan slechts te betreuren viel, dat het eerst ter vergadering gedrukt werd rondgedeeld. Uitroerig had de heer Nicolaï, an de hand der ervaring met de bevolkingsregisters opgedaan in de beide landen waar de bijhouding dier registers voor de gemeentebesturen is verplichtend gesteld (België eu Nederland) ${ }^{1}$ ), men mag wel haast zeggen de onmisbaarheid der bevolkingsregisters voor de administratie, en hun hooge waarde voor de ontwikkeling der bevolkingsstatistiek in het licht gesteld. De conclusie van zijn rapport was dan ook een aandrang bij het Institut om de wensch eener algemeene invoering van bevolkingsregisters uit te spreken.

Hiertegen kwam echrer, met name van Fransche zijde, krachtig verzet. Werd vroeger in het Institut ter bestrijding van de bevolkingsregisters de, met het oog op België en $\mathrm{Ne}$ wel geheel ongegrond gebleken, vrees uitgesproken, dat zij het periodiek houden van volkstellingen zouden in gevaar brengen, thans werd hiervan gezwegen. Daarentegen stelden de heeren Delatour, Guyot en anderen het voor, als zoude de verplichting aan de ingezetenen op te leggen om van vestiging en vertrek aangifte te doen, een inbreuk maken op de "Freizügigkeit" der bevolking. Zelfs vreesde men, dat invoering van zoodanige verplichting tot ernstige, sociale moeilijkheden zoude leiden, omdat de arbeiders zich in hun belangen er door bedreigd zouden achten! Het viel den rapporteur en ondergeteekende, gesteund door den heer von Mayr, niet moeilijk deze bezwaren zakelijk te weerleggen, en te betoogen dat voor statistici de wenschelijkheid van het hebben van bevolkingsregisters toch niet twijfelachtig kan zijn. En het gelukte ten slotte in de sectie met een kleine meerderheid van stemmen de volgende

1) Eigenlijk zoude ook Italië tot deze landen gerekend moeten worden. De bijhouding der registers laat daar echter, naar het schijnt, alles te wenschen over, zoodat het instituut daar eigenlijk slechts in naam bestaat. 
conclusie aangenomen te krijgen: l'Institut International de Statistique émet le voeu de voir $1^{\circ}$ les états qui n'ont pas encore de régistres de population en décider la création, de préférence à titre obligatoire; $2^{\circ}$ les états sur les territoires desquels l'nsage de ces régistres est facultatif, généraliser le système et le rendre obligatoire pour toutes les communes ou municipalités".

De door den rapporteur mede in den vorm van een resolutie gegoten wensch, dat tusschen de verschillende staten eene geregelde uitwisseling van verhuisbiljetten betreffende vestiging in den vreemde mocht worden tot stand gebracht, werd door hem, als zijnde in dit stadium der zaak, en met het oog op de felle oppositie tegen de geheele instelling der bevolkingsregisters, prematuur, teruggenomen ${ }^{1}$ ).

De oppositie liet het er echter na de behandeling der zaak in de sectie niet bij zitten, en toen de daar aangenomen conclusies aan de algemeene vergadering ter bekrachtiging werden voorgelegd, ontspon zich de discussie opnieuw, en werd er nadruk op gelegd dat door het woordje "obligatoire" aan de gemeentelijke autonomie dreigde afbreuk te worden gedaan. Het gevolg was, dat de vergadering in plaats van de door de sectie aangenomen conclusie, zich vereenigde met een voorstel-March (Parijs) van dezen inhoud: "l'Institut émet le voeu que l'usage des régistres de population se généralise", eene redactie die wel bezien de oppositie niet in het minst kon bevredigen, en dau ook nog vrij wat tegenstemmers vond.

Er was in deze discussie zóóveel onbegrijpelijk misverstand, dat er achter de oppositie een diepere grond verborgen moest zijn. Het schijnt dat dit inderdaad het geval was, en de Fransche leden van het Institut in de eerste plaats op politieke motieven vall de instelling der bevolkingsregisters afkeerig waren. Het is zeker te betreuren dat de hoogst verdienstelijke arbeid van den heer Nicolaï geen beter onthaal vond. De kans, dat de behandeling dezer zaak ter Loudensche vergadering aan de uitbreiding der bevolkingsregisters zal blijken bevorderlijk te zijn geweest, is nu ongetwijfeld niet zeer groot.

1) De vraag kan echter rijzen of niet het tot stand komen van zoodanige overeenkomst tusschen België en Nederland reeds thans voor beide landen van groot nut zoude kunnen zijn. 
De heer Schloss, van het Londensche Labour Department, die zich reeds meermalen door het bewerken van onderzoekingen op het gebied der loonstatistiek had onderscheiden, vestigde de aandacht van het Instituut opnieuw op de groote moeilijkheden welke aan eene, toch zoo werschelijke internationale vergelijking van het beschikbare loonstatistisch materiaal in den weg stann. Hij stelde daarom voor, vanwege het Institut tot de statistische bureaux, die zich in de verschillende landen met arbeidsstatistiek bezig houden, de uitnoodiging te richten om, volgens onderlinge afspraak met geregelde tusschenpoozen ieder in zijn land naar eenvormige beginselen speciale onderzoekingen in te stellen, alle op hetzelfde tijdstip betrekking hebbende, welke onderzoekingen zich zouden bepalen tot de loonen van telkens vooraf overeen te komen groepen van werklieden. De uitkomsten zouden dan wederkeerig door de bureaux aan elkander worden medegedeeld.

De denkbeelden van : den heer Schloss vonden in beginsel instemming. Echter werd tegen zijn voorstel, door den voorzitter der sectie het bezwaar geopperd dat het Institut, indien het werd aangenomen, gelijk het daar lag, zijn taak uit handen zou geven en overdragen op de chefs der statistische bureaux. Rekening houdend met het feit, dat het Institut zich reeds vroeger (te Bern en te Weenen) met de kwestie der loonstatistiek had bezig gehouden, stelde hij daarom voor het rapport van den heer Schloss te verwijzen naar het comité dat destijds de loonstatistiek in studie had genomen, en dit comité, waarin sedert eenige vacatures waren gekomen, aan te vullen o. a. met den ondergeteekentle. Dienovereenkomstig werd besloten.

Had de heer Schloss verzuimd rekening te houden met de voorgeschiedenis in het Institut van het door hem behandelde onderwerp, hetzelfde was het geval met den heer Loch (Londen) die in een rapport enkels desiderata toelichtte met betrekking tot de statistiek van het armwezen. Deze statistiek zoude, naar ziju oordeel, moeten gevestigd worden op den grondslag van bijzondere tellingen, door de armbesturen op een of meerdere dagen in het jaar te houden. De heer von Inama Sternegg, die in Christiania reeds met gunstig gevolg had gepleit voor het beginsel der doorloopende bedeeldenregisters, stelde, ten einde te voorkomen, dat wellicht in eene slecht bezochte vergadering een 
overhaast besluit mocht worden genomen, verdaging tot de eerstvolgende zitting van het Institut voor, met uitnoodiging aan den heer Loch om tegen die zitting een meer uitgewerkt rapport over deze zaak te willen uitbrengen. De vergadering vereenigde zich met dit voorstel.

Het beginsel der telkaarten heeft, sedert het op statistisch gebied het eerst werd toegepast, voortdurend zijn deugdelijkheid in steeds ruimer kring erkend gezien. Zijn invoering heeft niet slechts de techniek der statistiek in hooge mate verbeterd, maar ook de uitkomsten van het statistisch onderzoek rijker el veelzijdiger gemaakt, dan zonder toepassing van het kaartenstelsel zoude zijn mogelijk geweest. De heer de Wendrich (Petersburg) kwam thans de invoering van het kaartenstelsel bepleiten als groudslag voor de statistiek van het vervoer op de spoorwegen. In Rusland en in Frankrijk (Noord en Zuid) is het beginsel van de "feuilles de route" die het rollend materiaal der spoorwegen begeleiden, reeds tot groote tevredenheid ingevoerd. Zelfs heeft het, door het overzicht te vergemakkelijken van het gebruik dat van de waggons gemaakt wordt, in Frankrijk tot niet onbelanrijke besparingen geleid. Men overweegt er thans de invoering van een "bulletin de traction" voor de locomotieven. De sectie, en evenzoo later het plenum, met belangstelling kennis genomen hebbende van de mededeelingen van den heer de Wendrich, vereenigden zich met de door hem voorgestelde conclusies aldus luidende: l'Institut, cousidérant que d'après les résultats obtenus, le bulletin de parcours, attaché à chaque wagon, constituerait la base sérieuse d'une statistique nationale et internationale des moyens de transport, appelle l'attention des administrations des chemins de fer d'Etat ou privées sur ce système. Elle proroge les pouvoirs de la Commission (voor de internationale spoorwegstatistiek) et charge le Président de cette commission de receuillir auprès des administrations et des gouvernements les renseignements qui permettraient d'aboutir par ce moyen à uue statistique internationale.

Door den heer Livi, werkzaam bij den geneeskundigen dienst aan het Ministerie van Oorlog in Rome, werden belangwekkende 
mededeelingen gedaan nopens de uitkomsten van authropometrische onderzoekingen in het Italiaansche leger. Zoowel de lichaamslengte als het gewicht der soldaten wordt daar, in verband met den duur van den dienst en den leeftijd der soldaten, geregeld nagegaan. In de uitkomsten van het onderzoek, welke door hem graphisch waren toegelicht, was voorts met het vroeger beroep en de woonplaats der soldaten rekening gehouden. Het bleek o. m. dat de lichaamslengte der 20 jarigen (het rijk in zijn geheel genomen) bij de soldaten van minimale lengte, d. w. z. beneden 1.60 M. en minimaal gewicht, d. w. z. beneden э7 KG., na één jaar dienst was toegenomen met 8,5 millimeter, van' hun gewicht met $3 \mathrm{KG}$.; en evenzoo bij de soldaten met maximale lengte (1.70 M. of langer) en gewicht (boven $66 \mathrm{KG}$.) de lichaamslengte was toegenomen met 4,5 millimeters en het gewicht met 2 KG. Voorts bleek, om nog een opmerkelijk resultant van het ouderzoek te vermelden, de lichaamslengte bij uit landelijke beroepen af komstige lotelingen belangrijk meer te zijn toegenomen dan bv. bij studenten. Op het gebied der anthropologie is ook hier te lande nog zeer veel te onderzoeken, en het leger biedt daartoe een uitnemend materiaal. Het is zeer te wenschen, dat hetgeen op dit gebied teu onzent reeds gedaan werd regelmatig en methodisch wordt voortgezet en uitgebreid. Uitstel is hier afstel. Wat in eenig jaar ongedaan blijft kan nimmer meer worden ingehaald.

Naarmate de verplichte arbeidersverzekering zich over meerdere landen uitstrekt, ontstaat de behoefte, niet alleeu aan internationale regelingen van materieelen aard nopens den rechtstoestand, met betrekking tot deze verzekeringen, van arbeiders buiten de grenzen van het eigen land werkende, (regelingen in den geest derhalve als tusschen Frankrijk en Italië, en tusschen België en Luxemburg werden gesloten), doch ook en niet minder aan regelingen welke in staat stellen de uitkomsten dezer verzekering en de ervaring daarmede van land tot land verkregen onderling te vergelijken. Te Bern was in 1895, op voorstel van Bertillon (Parijs) reeds de wensch uitgesproken, dat voor de ongevallenstatistiek allerwege het in Duitschland aangenomen kader gevolgd zoude worden, doch de Londensche zitting was de eerste in welke het Institut zich meer opzettelijk met de statistiek der 
arbeidersvorzekering bezig hield. Er ligt hier een vruchtbaar veld van werkzaamheid voor het Institut open, warop het zich ongetwijfeld nog vaak zal moeten bewegen. De beraadslagingen werden ingeleid door de heeren Cheysson en Kögler, Directeur der Arbeiter Unfall Versicherungsanstalt voor NederOostenrijk te Weenen. De behandeling van deze aangelegenheid wekte veel belangstelling en voerde ten slotte tot de aanneming van de volgende resolutiën.

L'Institut International de Statistique, considérant que la statistique des accidents est indispensable pour guider les industriels dans les mesures de prévention et de securité du travail; les établissements d'assurance, dans la fixation de leurs primes; le législateur, dans la rédaction des lois sociales, et l'administrateur, dans l'application de ces lois;

$\mathrm{Vu}$ les résolutions des Congrès internationaux des accidents et des assurances ouvrières de Paris; de Berne, de Milan, et notamment de Düsseldorf en 1902;

Vu l'utilité d'arriver à l'unfication des statistiques nationales d'accidents dans la mesure que comportent pour chaque pays les exigences de sa législation et de son organisation d'assurance,

Recommande aux divers pays de conformer leur statistique nationale des accidents aux principes généraux ci-après :

(1) On s'efforcera d'obtenir, pour chaque industrie, son "Coeffcient de Risques," c'est-à-dire le rapport du nombre des viclimes d'accidents ou des sinistrés au nombre des ouvriers soumis au risque ou des sinistrables.

(2) Le nombre des sinistrés sera fourni par les déclarations d'accidents, les fiches de sinistres, et les décisions de justice.

(3) Le nombre des sinistrables sera calculé, en ramenant le nombre des ouvriers effectifs au nombre d'ouvriers-types, d'unités ouvrières, ou de voll-arbeiter, c'est-à-dire d'ouvriers ayant travaillé 300 journées pleines, de chacune 10 heures.

(4) Les éléments de ce nombre proviendront des établissements d'assurance.

Là où l'assurance, l'étant pas obligatoire, n'embrasse pas la totalité des assujettis, chaque pays s'arrangera pour trouver dans son organisation particulière les moyens de combler les lacunes relatives aux non-assurés.

(5) Les différeuts pays sont invités à arrêter une classification 
industrielle, qui ne soit ni trop large ni trop étroite, en s'astreiguant, autant que possible, à l'identité des grandes divisions, sauf à chaque pays à les subdiviser, d'après les convenances de ses industries nationales, les cadres de son recensement professionnel, et les catégories en usage dans la pratique de ses assurances.

(6) Des tableaux spéciaux classeront les cnuses et la nature des lésions par industrie et les rapprocheront de leurs conséquences, conformément aux classifications adoptées pas la loi de chaque pays pour la réparation des accidents d'après leur gravité.

(7) La statistique enregistrera, par industrie, le nombre des veuves et des orphelius, correspondant aux ouvriers tués.

(8) Elle classera de même par industrie les victimes, d'après l'âge, le sexe et l'état civil, en utilisant des déclarations d'accidents et les statistiques judiciaires.

L'Institut nomme une Commission spéciale, chargée de dresser, pour la prochaine session, les cadres de cette statistique internationale, en conformité aux principes qui précèdent.

A cet effet la Commission se mettra en rapport avec les services compétents de chaque pays, avec le comité permanent des congrès internationaux des accidents et des assurances ouvrières, et avec le Congrès International des Accidents et des Assurances Ourrières, qui doit se tenir à Vienne en septembre 1905.

Het feit, dat het Institut verscheiden chefs van stedelijke statistische bureaux onder zijne leden telt, heeft $o$. m. het gelukkig gevolg, dat ann de stedelijke statistiek en met name aan de stedelijke demographie op de programma's en zittingen een plaats pleegt te worden ingeruimd. Waar de rijks statistiek zich, om finantieele en andere redenen, veelal wel moet bepalen tot extensieve bewerking der stof, is de arbeid der op kleiner terrein en daardoor meer intensief werkende stedelijke bureaux voor de ontwikkeling der statistiek van hooge waarde. Ter Londensche zitting was het Dr. Bleicher (Frankfort), die een onderwerp tot het domein der stedelijke statistiek behoorende, t. w. de sterfte in de steden, inleidde. Dr. Bleicher legde er nadruk op, dat het, met het oog op de moderne ontwikkeling van het verkeer, dat er toe leidde dat een steeds grooter wordend deel der stedelijke bevolking buiten grat wonen en de stad 
slechts als plaats voor uitoefening van beroep of bedrijf gaat beschouwen, noodig is het waarnemingsgebied voor de stedelijke demografie te verruimen. Op zijn voorstel vereenigde zich de sectie met de volgende conclusies: pour faire des études spéciales sur la question de la mortalité de la population urbaine et rurale dans leurs relations réciproques, il serait indispensable d'exécuter des travaux monographiques relatifs à des territoires économiques assez étendus el qui regardent surtout la totalité des phénomènes du mouvement de la population. Ces travaux exigent aussi avant tout de prendre en considération le développement historique des conditions en question.

Ter vorige zitting van het Institut was Prof Lexis (Göttingend) op voorstel van Levasseur, naar aanleiding van een wensch uitgesproken door het demographische congres, uitgenoodigd zich te belasten met het ontwerpen van een kader voor een internationale statistiek der tuberculose. De heer Lexis was echter van oordeel, dat deze taak beter voor eene commissie onder medisch deskundige leiding kon worden volvoerd. De conclusie van zijn rapport, waarmede de vergadering zich vereenigde was dan ook deze dat, onder voorzitting van Dr. Bertillon, eene commissie zou worden belast met het onderzoek van het vraagstuk der tuberculose-statistiek, zoowel wat betreft de mortaliteit als de morbiditeit, daarbij inzouderheid onderzoekende den omvang eu de uitkomsten der bestrijding van deze ziekte in ziekenhuizen, sanatoria en herstellingsoorden.

De heer Kiaer (Christiania), die voor enkele jaren een klassiek werk over den loop der huwelijksvruchtbaarheid in het licht zond, bepleitte te Londen overtuigend de noodzakelijkheid om deze demographisch zoo hoogst gewichtige materie; grondiger te onderzoeken dan tot.dusver in de meeste landen het geval is geweest. Met name wenscht hij onderzoek naar het verband tusschen de navolgende gegevens en de huwelijksvruchtbaarheid: de duur van het huwelijk; ouderdom van man en rrouw bij het aangaan van het huwelijk; aantal der levendgeboren kinderen tot op het tijdstip der waarneming resp. tot aan de ontbindiug des huwelijks door dood of echtscheiding; de volgorde der geboorten en de tusschenruimte tusschen twee bevallingen; de kindersterfte en de mortinataliteit; de leeftijd der ouders op het tijdstip der geboorten; hun woonplaats (stad en land); het be- 
roep van den vader en zijn sociale positie. Voor zooveel noodig en mogelijk moeten deze verschillende statistieke gegevens voorts in onderling verband worden gebracht. De aanstaande invoering hier te lande van telkaarten ten behoeve van de geboorte- en huwelijksstatistiek, zal het mogelijk maken ook ten onzent aan deze uiterst gewichtige hoofdstukken der demographie meer andacht te wijden, dan tot dusver kon geschieden.

Prof. B. Földes (Budapest) die meer dan eenmaal belangrijke onderzoekingen publiceerde nopens deu loop der graanprijzen in de $19^{\mathrm{e}}$ eeuw in de onderscheidene landen legde aan het Institut een samenvatting van de uitkomsten van zijn onderzoek over, daarbij tevens wijzende op de moeilijkheden welke op dit gebied overwonnen moeten worden, daar de grondslagen der prijsstatistiek in de verschillende landen veelal zeer uiteenloopen. Sommige landen publiceeren prijzen voor graan van gemiddelde hoedanigheid, andere voor graan van verschillende kwaliteiten; de prijzen zijn soms hoogste of laagste, soms gemiddelde prijzen, welke laatste dan weder niet altoos volgens dezelfde methode berekend zijn. Op zijn voorstel vereenigde de vergadering zich met de volgende conclusie: vu la grande importance que la statistique des prix de grains soit fondée sur la base la plus scientifique, l'Institut Interuational de Statistique demande pour sa prochaine session de son comité des prix un rapport sur la méthode la plus correcte de receuillir et de faire comparer les données internationales.

Op het programma van schier elke zitting verschijnt het vraagstuk der internationale vergelijkbaar-making van de handelsstatistiek, een vraggstuk aan welks oplossing men geneigd is te wanhopen wanneer men kennis neemt van de groote verschillen welke thans nog bestaan in de stelsels door de verschillende landen ter zake gevolgd. De heer Bateman (Londen) had aan de hand der jongste statistieken nog eens een overzicht van deze stelsels (voor sommige landen ware stelselloosheid het juiste woord) bewerkt.

Op het banket door den Lord-Major in Mansion House het Institut angeboden, ging bij het dessert de traditioneele "love cup" rond. Deze ceremonie gaf den heer de Foville annleiding tot een geestige speech, waarin hij de hoop uitsprak, dat de arbeid van het Institut er toe mocht leiden, dat de statisticus 
zich eerlang zou kunnen verheugen in het bezit van internationaal-homogeen cijfermateriaal, aangeboden in eenvormige kaders. Met betrekking tot de handelsstatistiek, waarbij zich overigens de behoefte aan eenvormigheid het eerst en het dringendst doet gevoelen, zal echter de wensch van den heer de Foville vooreerst nog wel niet in vervulling komen.

Gevolg gevende aan eene uitnoodiging van de Deensche regeering, zal de eerstvolgende zitting van het Institut in 1907 te Kopenhagen worden gehouden.

C. A. Verriju Stuart. 